\title{
Brain-Derived Neurotrophic Factor Attracts Geniculate Ganglion Neurites during Embryonic Targeting
}

\author{
Natalia Hoshino Phillip Vatterott Amina Egwiekhor M. William Rochlin \\ Biology Department, Loyola University Chicago, Chicago, III., USA
}

\section{Key Words}

Axon · Guidance $\cdot$ Neurotrophin • Epithelium • Taste ·

Development

\begin{abstract}
Geniculate axons are initially guided to discrete epithelial placodes in the lingual and palatal epithelium that subsequently differentiate into taste buds. In vivo approaches show that brain-derived neurotrophic factor (BDNF) mRNA is concentrated in these placodes, that BDNF is necessary for targeting taste afferents to these placodes, and that BDNF misexpression disrupts guidance. We used an in vitro approach to determine whether BDNF may act directly on geniculate axons as a trophic factor and as an attractant, and whether there is a critical period for responsiveness to BDNF. We show that BDNF promotes neurite outgrowth from geniculate ganglion explants dissected from embryonic day (E) 15, E18, infant, and adult rats cultured in collagen gels, and that there is a concentration optimum for neurite extension. Gradients of BDNF derived from slow-release beads caused the greatest bias in neurite outgrowth at E15, when axons approach the immature gustatory papillae. Further, neurites advanced faster toward the BDNF bead than away from it, even if the average amount of neurotrophic factor encountered was the same. We also found that neurites that contact
\end{abstract}

BDNF beads did not advance beyond them. At E18, when axons would be penetrating pregustatory epithelium in vivo, BDNF continued to exert a tropic effect on geniculate neurites. However, at postnatal and adult stages, the influence of BDNF was predominantly trophic. Our data support a role for BDNF acting as an attractant for geniculate axons during a critical period that encompasses initial targeting but not at later stages.

Copyright $\odot 2010$ S. Karger AG, Basel

\section{Introduction}

Lingual taste axons exhibit a high degree of fidelity during initial targeting to gustatory papillae [1-5]. Several in vivo studies suggest that brain-derived neurotrophic factor (BDNF) is critically involved in the final targeting of geniculate afferents to fungiform papillae. BDNF mRNA is found throughout fungiform papilla epithelium when geniculate growth cones are arriving at this epithelium [6-8]. BDNF mRNA then becomes restricted to the pre-taste bud portion as geniculate axons penetrate this region of the epithelium [6-8]. In BDNF-/- mice, few geniculate axons are found in fungiform papilla epithelium [9-12], indicating that BDNF is necessary for normal pathfinding. When BDNF is over-

\section{KARGER}

() 2010 S. Karger AG, Basel

Fax +41613061234 E-Mail karger@karger.ch www.karger.com www.karger.com/dne
Assoc. Prof. M. William Rochlin

Loyola University Chicago, Biology Department, LSB 317B

1032 W. Sheridan Road

Chicago, IL 60660 (USA)

Tel. +1 773508 2450, Fax +1 773508 3646, E-Mail wrochli@luc.edu 
expressed in tongue mesenchyme or throughout the epithelium, axons target the sites of overexpression [13-15]. Clearly, BDNF is necessary for normal taste nerve patterning and capable of redirecting axons in vivo, but whether it acts directly as an attractant for geniculate axons has not been shown.

Neurotrophic factors such as BDNF are pleiotropic cues. They have the capacity to promote axon extension in vivo $[16,17]$ and may also be attractants for peripheral sensory axons [18-22]. BDNF has been shown to directly attract neurites of a variety of central and peripheral neurons in vitro [23-28]. However, neurotrophic factors also promote neuronal survival $[29,30]$, regulate synaptic communication [31], induce apoptosis in nonneuronal cells [32], and influence differentiation in a variety of systems $[33,34]$. Perturbations in pathfinding arising from altering the levels of a pleiotropic cue could be indirect, via nonneuronal targets of the cue, or could result from the suspected cue altering the ability of the growth cone to respond to the actual guidance molecule (e.g. by preventing growth or causing maximal growth) [35-37]. Therefore, it is important to complement in vivo manipulations of neurotrophic factor expression with in vitro studies in which the capacity of the neurotrophic factors to act directly on the cells of interest is tested and developmental changes in the response of those cells can be evaluated.

Whether BDNF acts as an attractant in vivo after initial innervation is difficult to address because initial innervation is disrupted in mice in which BDNF expression has been perturbed. BDNF continues to be expressed throughout life in the subset of the taste cells that form classical synapses with afferents [38], raising the possibility that it continues to act as an attractant for geniculate axons. Taste cells undergo turnover throughout life [39], so it is possible that initial targeting is recapitulated during replacement of taste cells. In addition, regeneration of severed geniculate axons to taste buds occurs with specifity $[40,41]$, and BDNF could contribute to this. Furthermore, whether postnatal or older geniculate explants are responsive to neurotrophic factors postnatally has not been assessed. For these reasons, we also studied the influence of BDNF on neurites from postnatal and maturing geniculate ganglia in vitro.

\section{Materials and Methods}

The procedures for culturing explants are described in Rochlin and Farbman [42] but are outlined briefly below. Embryonic day (E) 1 is defined as the day the dam is found to be sperm positive. Explants were cultured in $35 \mu \mathrm{l}$ collagen I gels [embryonic and up to postnatal day (P) 7] or Matrigel (adult, BD Biosciences) on cover glasses in C10-2 medium. The MEM-based C10-2 medium contains 10\% fetal bovine serum (ATCC) and 2\% chick embryo extract (US Biological). Postnatal and embryonic ganglia were cultured for 2 days, but adult ganglia required 4 days in vitro. When ganglia and beads were cocultured, they were separated by distances ranging from 250 to $1,200 \mu \mathrm{m}$.

Neurite outgrowth was measured in the absence or presence of BDNF. The radius of the halo of outgrowth was determined by taking 2 or 3 measurements from the edge of the explant to the greatest extent of the halo (ignoring up to a few fascicles that extended beyond the halo). Neurite outgrowth measurements in bath application experiments that were designated as statistical outliers by Systat 12 ANOVA were removed from the analysis. We also removed explants that were both small and had outgrowth measurements that were half the mean or less, inferring that the ganglion was damaged. Significance was assessed by ANOVA using a Tukey correction for multiple comparisons ( $p<0.05$ was our criterion for significance). Each stage (E15, E18, and P1-7) was treated as its own comparison group for the Tukey corrections. At least 2 experiments were conducted in each case.

Affigel Blue beads (Biorad) were prepared essentially as described previously [43]. About $20 \mu \mathrm{l}$ of a bead slurry were aspirated and transferred to a siliconized $1.5-\mathrm{ml}$ centrifuge tube. Beads were washed 4 times with Dulbecco's phosphate-buffered saline (PBS, Invitrogen) to remove preservatives and equilibrate the beads. Approximately 15 beads in a volume of $1-2 \mu$ l were transferred to a $0.6-\mathrm{ml}$ tube, and BDNF was added to a final concentration of $5 \mu \mathrm{g} / \mathrm{ml}$. It is important to note that the neurotrophic factor must be prepared in PBS containing $1 \mathrm{mg} / \mathrm{ml}$ bovine serum albumin (BSA, Sigma). We believe that BSA binds to the high-affinity sites within the beads. Without blocking these sites, neurotrophic factor is not released by the beads. Beads were incubated on ice for at least $3 \mathrm{~h}$ prior to use and used within 1 week of preparation. Prior to use, beads were transferred to a Petri dish containing about $3 \mathrm{ml}$ of Dulbecco's PBS to remove neurotrophic factor that was not inside the beads. Beads were then transferred to a Petri dish containing about $2 \mathrm{ml}$ of C10-2 medium. Ganglia were transferred into this dish, and 1 bead and typically 2 or 3 ganglia were then transferred to the bottom collagen prior to adding the top collagen.

Immunohistochemistry was carried out as previously described [42]. An abbreviated description follows. For immunofluorescence of cultures, cover glasses were submerged in PBS (pH $7.4,37^{\circ} \mathrm{C}$ ) containing $4 \%$ paraformaldehyde, incubated at room temperature for $2 \mathrm{~h}$ or up to overnight at $4^{\circ} \mathrm{C}$, rinsed with PBS, labeled with an antibody against a marker protein in a PBS-based blocking solution containing 5\% dimethylsulfoxide (DMSO, Sigma) overnight, rinsed, and labeled with Cy3-conjugated donkey anti-mouse (Jackson Immunoresearch) or Alexa fluor 568 goat anti-mouse or goat anti-rabbit (Molecular Probes). Marker proteins included $2 \mathrm{H} 3$ mouse anti-neurofilament antibody (Developmental Studies Hybridoma Bank) for embryonic cultures, rabbit anti-PGP9.5 or 2H3 (AbD Serotec) for infant cultures (P1-7), and mouse anti- $\beta$-tubulin (Millipore) for adult cultures. All images of infant cultures are of $2 \mathrm{H} 3$ staining. Imaging and outgrowth assessment were carried out on labeled cultures as follows. Fluorescent images were obtained using a Zeiss Axiovert 100TV or an Olympus Fluoview 1,000 confocal microscope. To determine whether neurite outgrowth was biased (repelled or attract- 
ed) by beads, the halo of outgrowth was divided into quadrants. The proximal quadrant was that facing the bead and the distal quadrant was the opposite quadrant. An index of the length of axon outgrowth was obtained by measuring the distance from the edge of the explant to the edge of the outgrowth halo at 2 or 3 sites within the proximal or distal quadrant and averaging these measurements. Outgrowth was not always uniform within the quadrant, so the 2 or 3 measurement sites were taken from the 2 or 3 regions with the most robust outgrowth. Images for figures were prepared in Adobe Photoshop and contrast was enhanced.

\section{Results}

BDNF Stimulates Neurite Outgrowth from E15 through Adulthood; the Effects Are Stage-Dependent and There Is a Concentration Optimum

Dissections were carried out at 4 stages of development: E15, when geniculate axons have entered the tongue and begun to approach fungiform-papilla epithelium; E18, when geniculate axons have just entered the target epithelium [3]; during the first postnatal week (P1-7), when taste pores are opening [44]; and in adults $(\geq$ P30). In the absence of added neurotrophic factors, E15 geniculate ganglion explants appeared to disintegrate, and no neurites were observed (fig. 1a). With E18 explants, few 2H3-positive neuron cell bodies were observed after 2 days in vitro, and no measurable neurite outgrowth was observed (fig. 1b). P1-7 ganglion explants exhibited neurotrophin-independent outgrowth in collagen gels after 2 days (fig. 1c). Adult ganglia extended no neurites in collagen I gels for up to 4 days $(n=6)$, but several neurite fascicles were extended in Matrigel after 4 days (fig. $1 \mathrm{~d}, \mathrm{n}=11$ ). In summary, only in $\mathrm{P} 1-7$ ganglia did we consistently observe neurite outgrowth in the absence of added neurotrophic factors in collagen I gels.

BDNF stimulated neurite outgrowth at all stages, but was most effective on E15-P7 ganglion explants. In general, 25-50 ng/ml BDNF elicited the optimum outgrowth length. At E15 and E18, $10 \mathrm{ng} / \mathrm{ml}$ BDNF elicited sparse outgrowth (fig. 1a, b), suggesting that it was close to the threshold for stimulating neurite extension. This outgrowth was qualitatively much less dense than that observed with higher concentrations of BDNF. For E15 and E18 explants, 25 and $50 \mathrm{ng} / \mathrm{ml}$ BDNF stimulated significantly longer growth than 10, 100, and $200 \mathrm{ng} / \mathrm{ml} \mathrm{BDNF}$ (fig. 1a, b, fig. 2). The morphology of the outgrowth was similar at 25 and $50 \mathrm{ng} / \mathrm{ml}$ BDNF both for E15 and E18 explants (50 $\mathrm{ng} / \mathrm{ml}$ not shown), with many individual fascicles emitted from discrete sites along the surface of the ganglion. Beginning with $100 \mathrm{ng} / \mathrm{ml} \mathrm{BDNF}$, fewer indi- vidual fascicles were observed, and the outgrowth was emitted more uniformly and continuously along the surface than with $25 \mathrm{ng} / \mathrm{ml}$ BDNF. At $200 \mathrm{ng} / \mathrm{ml}$ BDNF, E15 and E18 neurite outgrowth appeared stunted, but only at E15 was this outgrowth significantly shorter than the outgrowth at $100 \mathrm{ng} / \mathrm{ml} \mathrm{BDNF}$.

For P1-7 ganglia, BDNF (10-200 ng/ml) promoted longer and thicker neurite fascicles than those observed without added neurotrophin (fig. 1c). As observed for E15 and E18 explants, 25-50 ng/ml BDNF yielded optimal neurite outgrowth length; however, the only significant differences in neurite outgrowth were between the explants treated with 25 (and 50) ng/ml versus the explants not treated with growth factor and versus those treated with $200 \mathrm{ng} / \mathrm{ml}$ BDNF. For adult ganglia cultured in Matrigel, $50 \mathrm{ng} / \mathrm{ml}$ BDNF stimulated more outgrowth than what was observed with no added neurotrophins (fig. $1 \mathrm{~d}, \mathrm{n}=8)$. However, the slow growth rate of adult neurites (4 days vs. 2 days for other stages) would interfere with assessing a response to a transient gradient of BDNF, so we did not carry out any additional experiments or quantitative analysis with adult ganglia. In summary, there is a concentration optimum for BDNFevoked neurite outgrowth at embryonic and postnatal stages.

Fig. 1. Stimulation of geniculate ganglion neurite outgrowth by BDNF. Ganglion explants from P7 and younger animals were grown in collagen I gels for 2 days $(\mathbf{a}-\mathbf{c})$, whereas adult ganglia were grown in Matrigel for 4 days (d). The concentrations (ng/ml) of BDNF used are indicated below the explant. At E15 (a) and E18 (b), virtually no outgrowth is observed without added BDNF, and only sparse outgrowth is observed with $10 \mathrm{ng} / \mathrm{ml} \mathrm{BDNF}$. Neurite extension was optimal at $25 \mathrm{ng} / \mathrm{ml}$ BDNF. At $100 \mathrm{ng} / \mathrm{ml}$ BDNF, the radius of the halo of outgrowth becomes smaller, and the morphology is altered, with fewer individual fascicles. BDNF at 200 $\mathrm{ng} / \mathrm{ml}$ inhibits E15 and E18 neurite outgrowth substantially. c P1-7 ganglia extend a halo of short, fine fascicles in the absence of exogenous neurotrophins. $10 \mathrm{ng} / \mathrm{ml}$ BDNF stimulates thicker and significantly longer fascicles than those observed without added neurotrophins. Although $25 \mathrm{ng} / \mathrm{ml} \mathrm{BDNF}$ is the optimal concentration for neurite length, higher concentrations, such as $200 \mathrm{ng} / \mathrm{ml}$, do not inhibit neurite extension to the same extent as with E15 and E18 ganglion explants (compare with a, b). d Adult geniculate ganglion explants extend few neurites when neurotrophic factors are not added, even after 4 days in growth factorrich Matrigel. BDNF (50 ng/ml) promotes additional neurite extension, but notably less than that seen at earlier stages. Bar $=250$ $\mu \mathrm{m}$. 

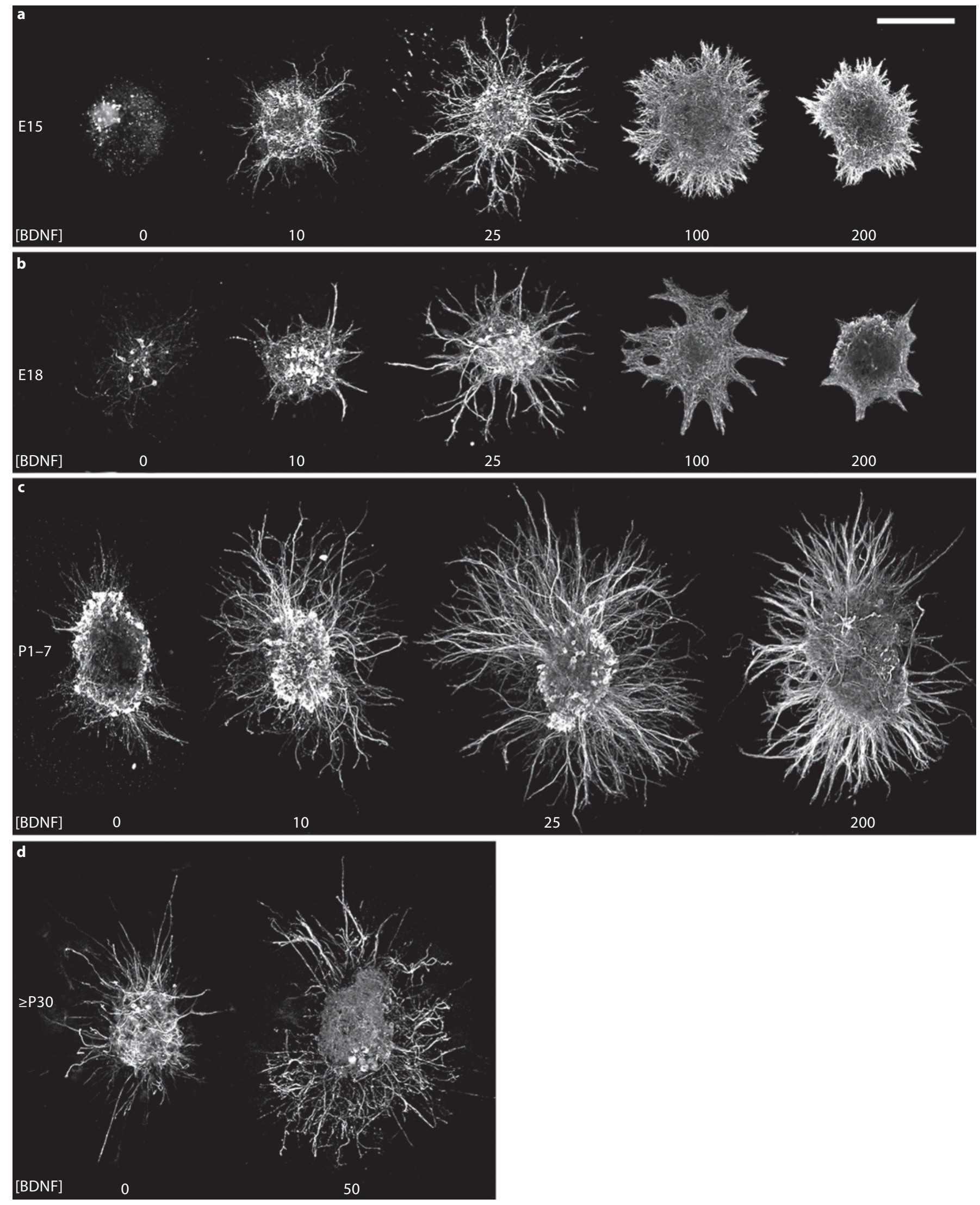

Brain-Derived Neurotrophic Factor 
Fig. 2. Chart depicting the influences of different concentrations of BDNF on the radius of the halo of neurites from geniculate explants at E15, E18, and P1-7. Error bars represent twice the SEM, which provides a more useful indication of which differences are significant [65] based on pairwise comparisons. As discussed in Materials and Methods, the Tukey correction was used to compensate for the multiple comparisons being done at each stage. Significant differences: only significant differences within the same stage are indicated. Note that for E15 and E18 explants that were not treated with growth factor, the outgrowth was zero in each case. Numbers of explants are indicated at the bottom of the bars. ${ }^{a}$ Significantly different from $0,10,100$, and $200 \mathrm{ng} / \mathrm{ml} \mathrm{BDNF}$; b significantly different from $100 \mathrm{ng} / \mathrm{ml}$ $\mathrm{BDNF}$, and ${ }^{\mathrm{c}}$ significantly different from 0 and $200 \mathrm{ng} / \mathrm{ml}$.

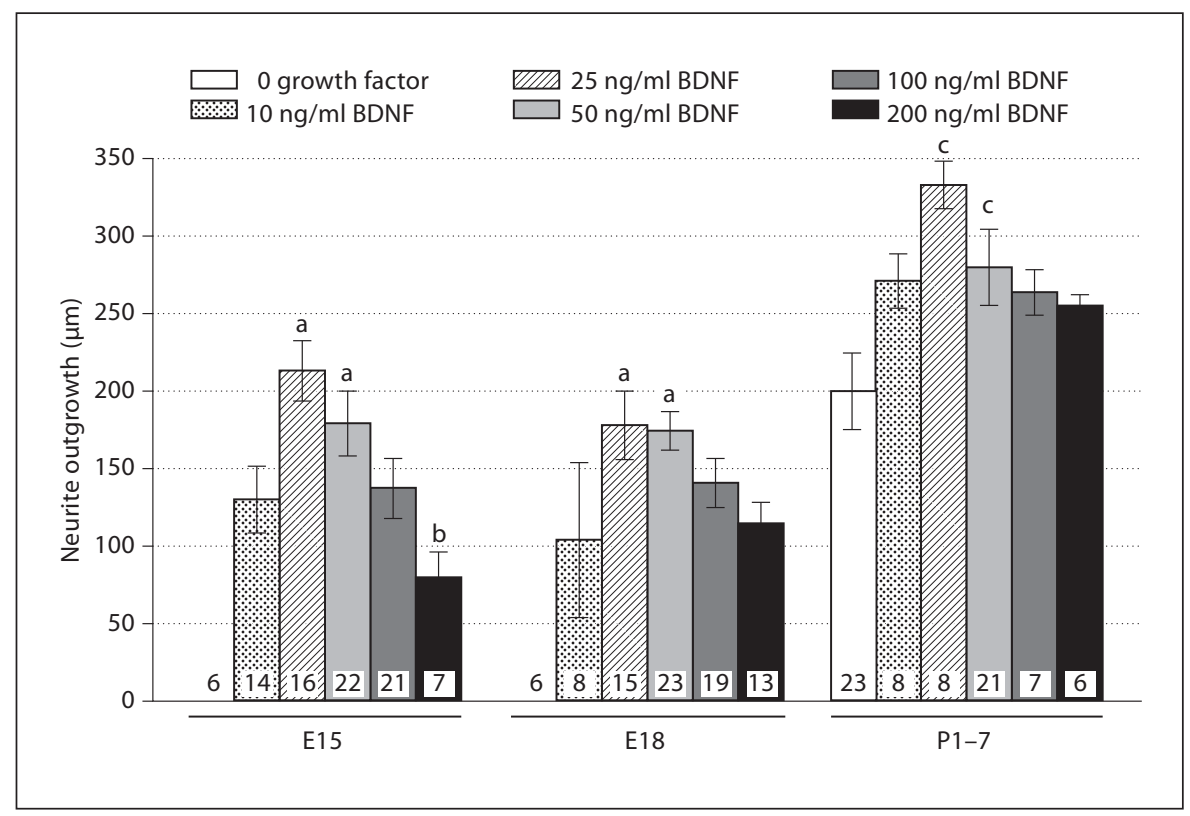

It is worth noting that we encountered considerable variability in the density (assessed qualitatively) and length of outgrowth for a given concentration of BDNF at E15 and E18. Individual ganglion explants exhibited variability around the perimeter of the explant: typically, one or two sides of the ganglion had longer growth than the rest of the perimeter. Variability was also observed among ganglia cultured in the same collagen gel and is likely due to the dissection: smaller ganglion explants tended to have fewer neurites and shorter growth. Other variability probably resulted from an interaction between the stage of the embryo and the batches or lots of reagents used to prepare the cultures. In early experiments (not shown in fig. 1 or incorporated into the analysis for fig. 2), $25 \mathrm{ng} / \mathrm{ml}$ BDNF elicited virtually no neurite outgrowth from E15 ganglion explants, and $100 \mathrm{ng} / \mathrm{ml}$ promoted robust growth. In later experiments (used for fig. 1, 2), 25 $\mathrm{ng} / \mathrm{ml}$ BDNF produced near-optimal outgrowth, and 100 $\mathrm{ng} / \mathrm{ml}$ BDNF produced shorter growth. However, with E18 ganglia, the reagents used earlier yielded modest but detectable neurite outgrowth, even without added growth factor, and better growth at 25 and $100 \mathrm{ng} / \mathrm{ml} \mathrm{BDNF}$ than that observed with reagents used for later experiments. Thus, outgrowth was better for E15 explants with the reagents used later, and better for E18 explants with the reagents used for our early experiments. The responses of geniculate neurites at each of the stages studied to gradients of BDNF, the focus of this study, were similar regardless of which reagent batches were used.
Fig. 3. BDNF attracts geniculate neurites during intralingual pathfinding and initial targeting. a-f E15 geniculate explants. Control beads $(\mathrm{Cn})$ do not bias E15 geniculate neurite outgrowth promoted by $100 \mathrm{ng} / \mathrm{ml}$ BDNF (a), but BDNF beads (BD) profoundly bias outgrowth (b). Note that the distant ganglion (on the left) has proximal outgrowth, even though it is further from the bead than the distal side of the other ganglion, which has no outgrowth. c Attraction to BDNF beads is saturable using $100 \mathrm{ng} / \mathrm{ml}$ BDNF in the bath. d E15 neurites do not grow beyond BDNF beads. Dots indicate the perimeter of the right half of the bead. Note that the ganglion on the right extends several fascicles toward the bead, all of which are longer than the neurites contacting the bead from the other ganglion. This indicates that sufficient time was permitted for neurite extension beyond the bead. e Neurite fascicles that contact control beads can grow beyond the bead (arrowhead). $\mathbf{f}$ High concentrations of BDNF inhibit outgrowth: fewer or no neurite fascicles are observed when $200 \mathrm{ng} / \mathrm{ml} \mathrm{BDNF}$ is provided in the presence of a BDNF bead than when $100 \mathrm{ng} / \mathrm{ml}$ BDNF is present (compare with c). g-I E18 geniculate explants. g Neurite growth stimulated by $25 \mathrm{ng} / \mathrm{ml} \mathrm{BDNF}$ is not biased by control beads. $\mathbf{h}$ Geniculate neurite outgrowth is strongly biased by BDNF-soaked beads. Note that neurites from the ganglion on the left are shorter than those from the ganglion on the right and they appear to stop prior to contacting the bead. As with E15 cultures, less outgrowth is observed when $200 \mathrm{ng} / \mathrm{ml} \mathrm{BDNF}$ is provided in the bath $(\mathbf{j})$ than when $100 \mathrm{ng} / \mathrm{ml}$ is provided in a BDNF bead culture (I). Neurites advance beyond a control bead in the presence of $100 \mathrm{ng} / \mathrm{ml} \mathrm{BDNF}$ (k, arrowhead) but not a BDNF bead (I). $\mathbf{m}$-o In these P2-3 cultures, there is little difference in the length of proximal and distal outgrowth, regardless of whether a control bead (m) is used or a BDNF bead (n). o In this stop assay, neurites extend preferentially on the side of the ganglion with the BDNF bead (just above the ganglion), but many neurites extend beyond the bead. Promoting growth beyond the source of BDNF is consistent with a trophic influence. Calibration bar $=250 \mu \mathrm{m}$. 

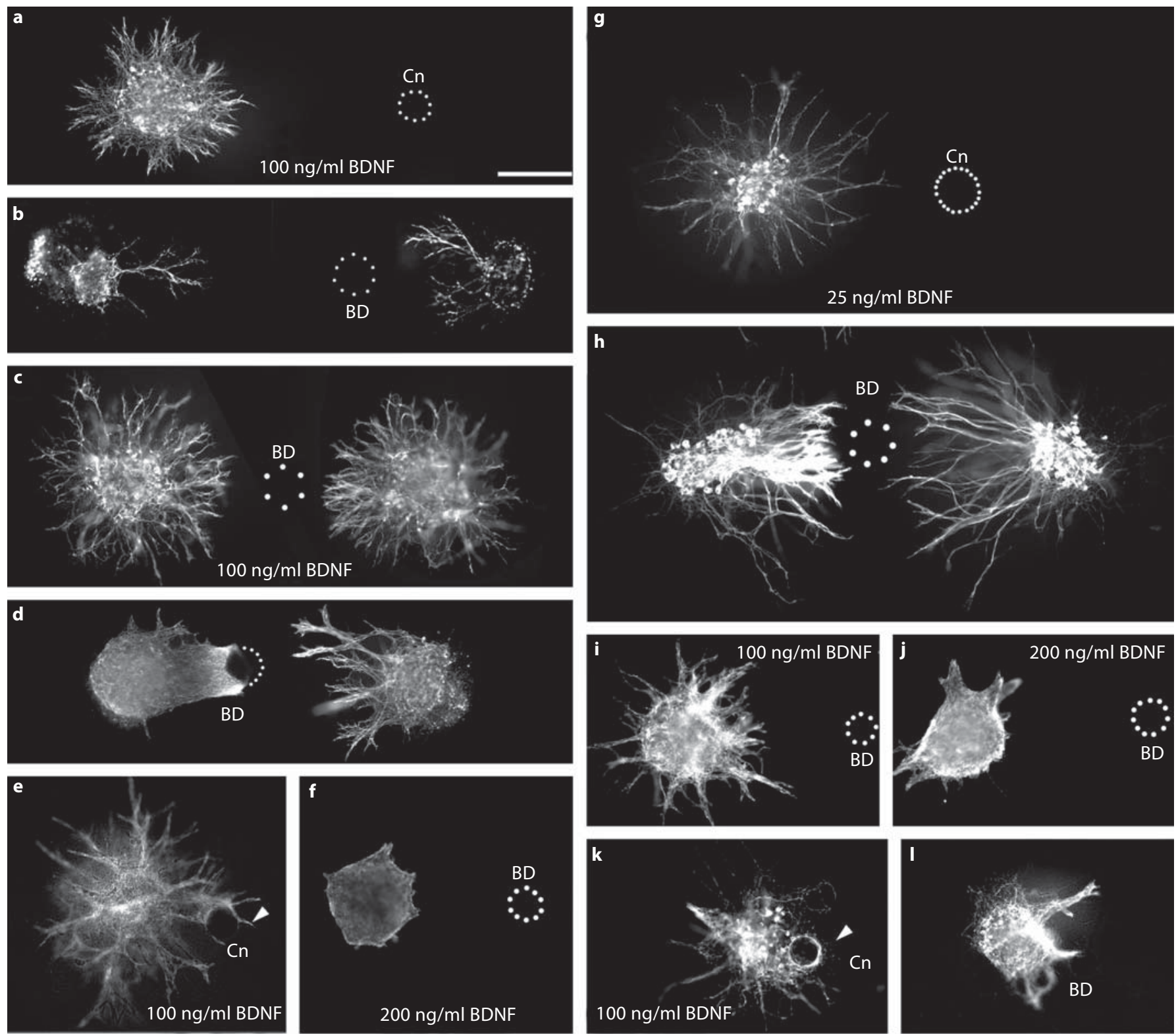

h
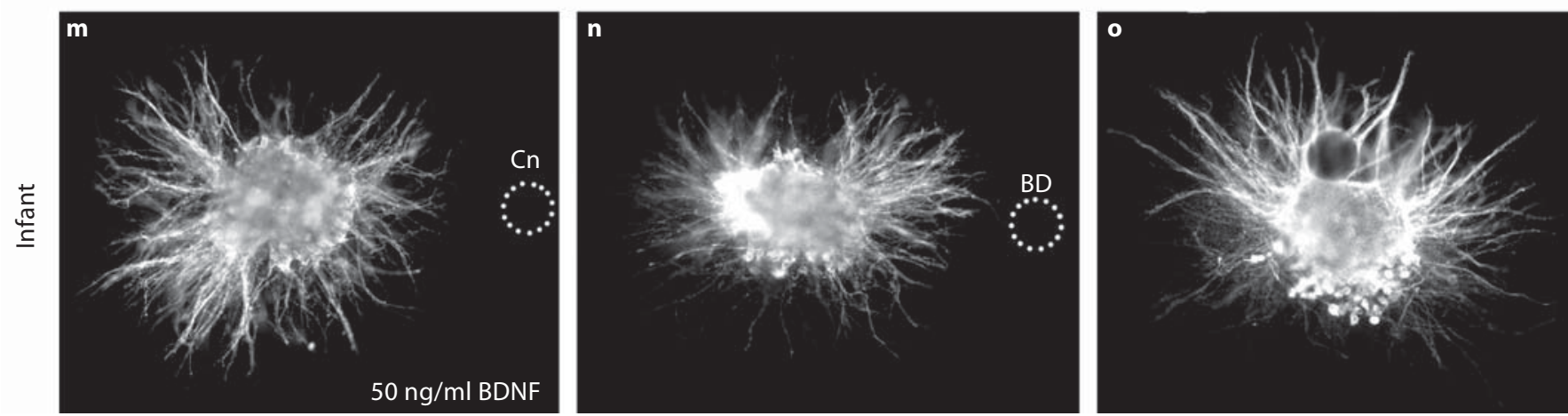


\section{BDNF Attracts E15 Geniculate Neurites}

To determine whether BDNF exerts a tropic effect on geniculate neurites, geniculate ganglia were cocultured with Affigel blue beads that had been soaked in medium (controls) or BDNF. For control cultures at E15 (during intralingual pathfinding), $100 \mathrm{ng} / \mathrm{ml} \mathrm{BDNF}$ was used to promote a halo of outgrowth (fig. 3a). This outgrowth was not biased by the control beads. Using BDNF beads and no added neurotrophic factor in the bath, geniculate neurites grew nearly exclusively toward the beads, exhibiting little or no distal outgrowth (fig. 3b): only 4 out of 19 ganglia exhibited distal outgrowth at this stage. For quantitation and statistical analysis, we measured the radius of the halo of outgrowth toward the bead and away from the bead (see Materials and Methods, fig. 4a) and took their ratio. The absence of distal outgrowth prevented us from determining the proximal-to-distal outgrowth ratio, so we instead used the ratio of distal to proximal neurite growth (fig. $4 \mathrm{~d}$ ). The outgrow th bias ratio for BDNF beads was significantly greater than for control beads $(\mathrm{p}<0.05$, ANOVA). When the medium was prepared with $25 \mathrm{ng} / \mathrm{ml}$ BDNF, attraction to the bead persisted (fig. 4a, d). We note that the experiments using $25 \mathrm{ng} / \mathrm{ml}$ were carried out early, using the reagents with which $25 \mathrm{ng} / \mathrm{ml}$ did not promote outgrowth from E15 geniculate ganglia. If $100 \mathrm{ng} / \mathrm{ml}$ BDNF was used in the medium, there was no longer a significant bias (fig. 3c, 4a, d), although a trend toward attraction was still evident. Thus, the attraction to BDNF beads is effective over a range of concentrations, and it is saturable. We attempted to determine whether the trend toward attraction could be eliminated by increasing the bath concentration of BDNF to $200 \mathrm{ng} / \mathrm{ml}$. As expected from our bath application results, outgrowth was too severely inhibited under these conditions to make quantitation of bias meaningful (fig. $3 \mathrm{f}, \mathrm{n}=8$ ).

To help distinguish between a purely trophic (growthpromoting) effect and a tropic (guidance) effect, we tested whether neurites extend more rapidly toward the BDNF bead than away from the bead when they are experiencing the same amount of BDNF. To this end, we used a '2-ganglion' paradigm in which 2 ganglia were placed at different distances from the same bead $[45,46]$. The minimum concentration of neurotrophic factor experienced by distal-growing neurites of the ganglion closer to the bead would be experienced at the edge of the halo of that outgrowth. Presumably, the concentration of BDNF at this distance from the bead is the same on both sides of the bead. If another ganglion explant in the same collagen gel were on the opposite side of the bead from the closer ganglion, such that its proximal edge is at least as far from the bead as the edge of the distal outgrowth from the ganglion near the bead, then the neurites of the distant ganglion would begin their journey at the same or at a lower concentration of BDNF than the minimum concentration experienced by the distal neurites of the closer ganglion. If the proximal neurites of the more distant ganglion are the same length as the distal neurites of the closer ganglion, then neurite growth rate is attributable to the amount of BDNF experienced, and it is not influenced by the direction of the gradient, i.e. BDNF is a trophic factor. If proximal neurites from the distant ganglion are longer than distal neurites of the closer ganglion, then neurites grow faster toward the source of BDNF than away from it, an indication that tropism predominates over trophism. When ganglia were positioned as described above, proximal outgrowth from the distant ganglion was significantly longer than distal outgrowth from the ganglion closer to the bead (pairwise $t$ test, $p<0.05$, fig. $4 a$ ). The near absence of outgrowth from the distal side of the closer ganglion is not due exclusively to inhibition by exposure to high BDNF levels because proximal outgrowth from the closer ganglion (which experiences a higher concentration of BDNF than the distal outgrowth) was not significantly different from the proximal outgrowth of the more distant ganglion (not shown). These data indicate that neurites from E15 ganglia grow faster toward a BDNF source than away, even if the average concentration of BDNF encountered is the same or less.

If attraction to BDNF takes precedence over its trophic effect, then neurites should not grow beyond the highest concentration of BDNF that they encounter. Therefore, we tested whether geniculate neurites would stop at or encircle BDNF beads. To this end, ganglia were plated close to the beads (within $100 \mu \mathrm{m}$ ) and sufficient time (2 days) was allowed to permit axons to grow beyond the beads. E15 neurites typically formed a net of neurites that cupped the part of the BDNF bead nearest the ganglion (6 of 8 cases), and did not extend beyond the bead (8 of 8 cases, fig. $3 \mathrm{~d}$ ). Neurites also cupped control beads (outgrowth was promoted with $100 \mathrm{ng} / \mathrm{ml} \mathrm{BDNF}$ ), but in 4 of 6 cultures, at least a few neurite fascicles grew beyond the beads, and there was substantial growth throughout the perimeter of the ganglion (fig. 3e). These proportions are significantly different $(\mathrm{p}<0.05$, Fisher's exact test, 2 -tailed). These observations are consistent with neurites targeting the highest concentration of BDNF.

\section{BDNF Attracts E18 Geniculate Neurites}

E18 geniculate neurites were significantly biased toward BDNF beads, although distal outgrowth was rou- 


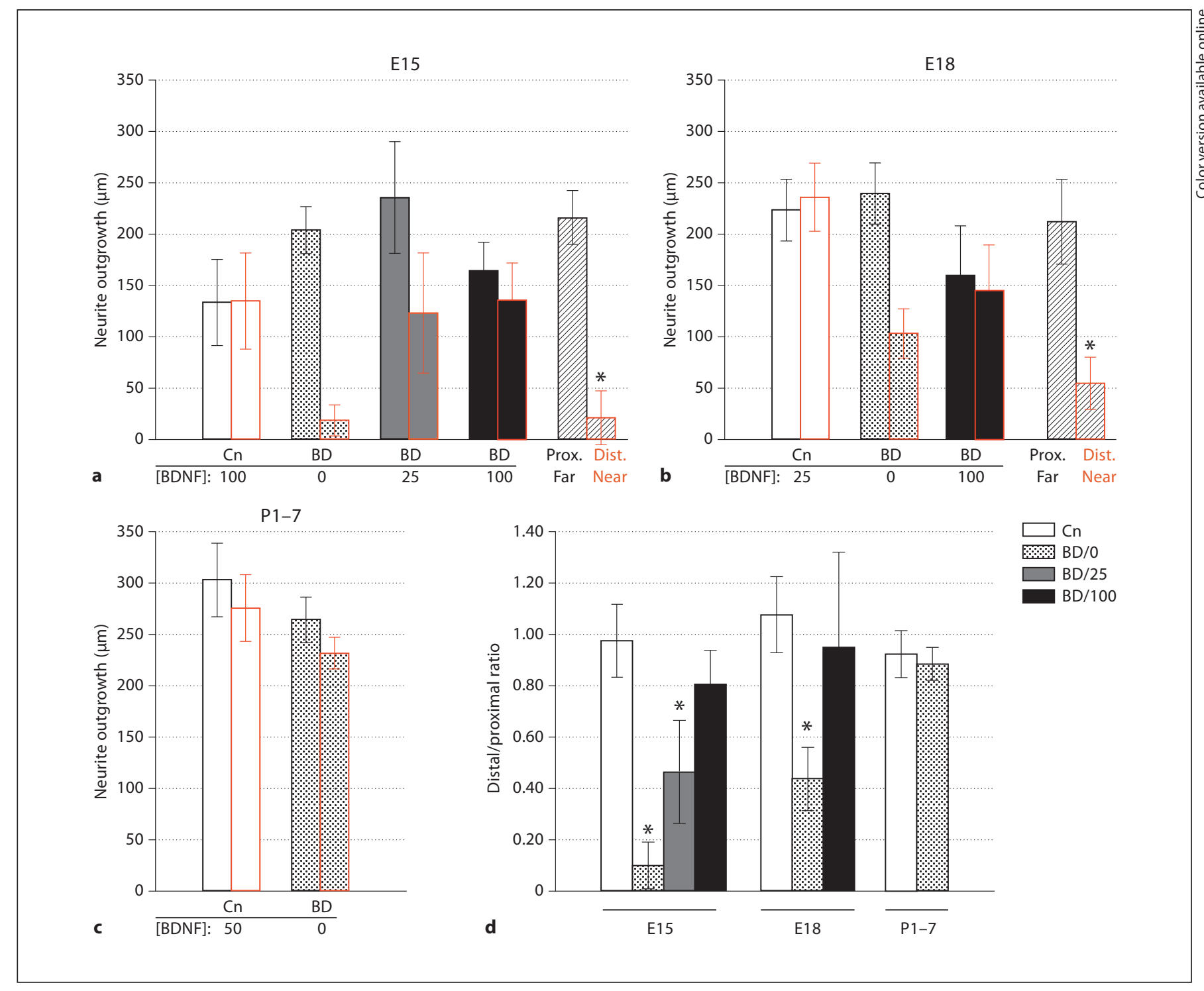

Fig. 4. Quantitation of neurite outgrowth in bead/ganglion cocultures. Proximal outgrowth (toward the bead) after 2 days in vitro is indicated by the left bar of each pair, distal outgrowth is indicated by the right bar. Error bars represent twice the SEM. a E15 geniculate ganglia. Outgrowth is not biased by control beads (Cn; white bars), but is strongly biased by BDNF beads (BD; dotted bars). Bias caused by BDNF beads is significant, even in the presence of $25 \mathrm{ng} / \mathrm{ml} \mathrm{BDNF}$ in the bath (grey bars), but not in the presence of $100 \mathrm{ng} / \mathrm{ml} \mathrm{BDNF}$ (black bars) (see d). In '2-ganglion' assays in which ganglia were positioned at different distances from the bead (see Results), the proximal outgrowth from the distant ganglion ('Prox. Far') is significantly longer ( $p<0.05$, paired-values $t$ test, 2-tailed) than the distal outgrowth from the closer ganglion ('Dist. Near'). b E18 geniculate ganglia. Control beads do not bias outgrowth (white bars), but BDNF beads do (dotted bars). No bias is detected if $100 \mathrm{ng} / \mathrm{ml} \mathrm{BDNF}$ is added to the bath (black bars). Outgrowth toward the beads from a distantly positioned ganglion ('Prox. Far') is significantly longer than outgrowth away from the bead by a ganglion positioned near the bead ('Dist. Near'). c Infant geniculate ganglia (P1-7). No significant bias in neurite outgrowth was observed with control beads $+50 \mathrm{ng} / \mathrm{ml} \mathrm{BDNF}$ in the bath, or with BDNF beads. $\mathbf{d}$ The ratio of the distal neurite growth to proximal neurite growth was calculated for most conditions. ANOVA was conducted to determine whether bead treatments differed significantly from one another. Asterisks mark treatments that differed significantly from the corresponding control treatments $(p<0.05)$, but additional significant differences are mentioned in Results. Bar legend: White bars correspond to distal:proximal outgrowth ratios using control beads and the bath concentration of BDNF indicated in $\mathbf{a}-\mathbf{c}$ for each stage. All other bars correspond to BDNF beads using the bath concentration (ng/ $\mathrm{ml}$ ) of BDNF indicated by the number following the 'BD'. Numbers: a control bead, 10; BDNF bead, 19; BDNF bead $+25 \mathrm{ng} / \mathrm{ml}$ BDNF, 12; BDNF bead + $100 \mathrm{ng} / \mathrm{ml}$ BDNF, 12; 2-ganglion assay, 9 pairs. b Control bead, 14; BDNF bead, 35; BDNF bead + $100 \mathrm{ng} /$ ml BDNF, 9; 2-ganglion assay, 11 pairs. c Control bead + BDNF bath, 18; BDNF bead, 21. 
tinely observed (fig. 3g, h, 4b, d). As a result of the distal outgrowth, the bias ratio at E18 was significantly less than that observed at E15. A bath concentration of $100 \mathrm{ng} / \mathrm{ml}$ BDNF saturated the biasing of neurite length by bead-released BDNF (fig. 3i, 4b). As was observed for E15 ganglia, neurite extension was inhibited when $200 \mathrm{ng} / \mathrm{ml}$ BDNF was provided along with a BDNF bead (fig. 3j). In 2-ganglion assays, when pairs of ganglia were positioned close to and far from the bead so that sensitivity to the direction of the BDNF gradient could be tested (as described above), outgrowth toward the BDNF bead was significantly greater than outgrowth away from the bead (fig. 4b). Proximal outgrowth from the closer ganglion was not significantly different from proximal outgrowth of the more distant ganglion, indicating that the distal outgrowth was not stunted by the high concentration of BDNF.

In stop assays, geniculate neurites that contacted a control bead were able to grow beyond the bead in 8 of 9 cases (fig. 3k). When BDNF beads were used, neurites extended to the bead but did not extend neurites beyond the bead in 4 out of 5 cases (fig. 3l). These proportions differ significantly ( $p<0.05$, Fisher's exact test, 2 -tailed). Similarly, whereas neurites only partially encircled BDNF beads (on the side of the bead facing the ganglion) in 4 of 5 cocultures, neurites completely encircled the beads in all 9 cocultures with control beads. Together with the strong bias in neurite growth toward BDNF beads, these data demonstrate that BDNF continues to exert a prominent tropic influence at E18.

\section{BDNF Beads Do Not Attract Postnatal Geniculate}

Neurites

BDNF promoted neurite extension after birth (fig. 1c), but BDNF-soaked beads did not significantly bias neurite extension (fig. $3 \mathrm{~m}, \mathrm{n}, 4 \mathrm{c}, \mathrm{d}$ ). Although the length of neurite outgrowth was not significantly biased by BDNF beads, the density, assessed qualitatively, was biased. In control cultures, only 3 of 18 ganglia exhibited a higher density of neurite outgrowth toward the control beads, whereas 14 out of 21 ganglia exhibited greater density of neurite outgrowth toward the BDNF bead than away from it. These proportions are significantly different $(\mathrm{p}<0.05$, Fisher's exact test, 2-tailed). In bead stop assays, 10 out of 12 ganglia extended neurites that contacted and grew beyond the bead (fig. 3o). These results suggest that BDNF has a predominantly trophic influence after birth.

\section{Discussion}

We report that BDNF acts directly as a chemoattractant for geniculate neurites at embryonic stages corresponding to initial targeting, but by $\mathrm{P} 1$, this chemoattractive influence is lost. These results provide crucial support for the possibility that BDNF is an attractant for geniculate axons during initial innervation in vivo $[4,12$, 47]. We also conducted dose-response studies using BDNF. These studies demonstrated that there is a concentration optimum for stimulating neurite extension in the case of BDNF. In addition to expanding our previous studies on embryonic geniculate ganglia, this is the first study to report the growth-promoting effects of BDNF on postnatal geniculate neurites.

In the absence of added neurotrophins, E15 and E18 ganglia did not extend neurites and no or little neuronal staining was observed within explants, indicating that most neurons did not survive for 2 days. P1-7 ganglia extended thin neurites under these conditions. The ganglia from postnatal and older rats are larger than those at embryonic stages, owing largely to the proliferation of nonneuronal support cells, which may provide more trophic support than is available at embryonic stages. In contrast to infant ganglia, adult ganglia exhibited little neurite growth in the absence of added neurotrophic factors, even when Matrigel (which contains a variety of neurotrophic factors) was used as the matrix and the culture time was doubled. Our unpublished observations indicate that the decline in spontaneous outgrowth is apparent after the end of the first postnatal week. This correlates with the opening of taste pores in fungiform papillae [44], but whether increased taste bud signaling induces this change in neurotrophin independence remains to be determined. The decline in neurite extension with adult explants may be due to a loss in intrinsic neuronal factors that are critical for regeneration, a change in substratum preference, or an alteration in trophic support provided by nonneuronal cells within ganglion explant [48].

Dose-response studies with bath-applied BDNF indicated that neurite length and morphology are affected by the concentration of BDNF. Intermediate concentrations of BDNF (25-50 $\mathrm{ng} / \mathrm{ml})$ resulted in longer neurites than lower and higher concentrations. Inhibition of outgrowth by high concentrations of nerve growth factor (NGF) and neurotrophin-3 (NT-3) was reported for other populations of sensory neurons and was interpreted as possibly reflecting desensitization [49-51]. Consistent with this possibility, continuous infusion of BDNF into the rat hippocampus decreased tyrosine kinase B (trkB) levels [52]. 
Note that BDNF was infused at much higher levels (1 mg/ $\mathrm{ml}$ ) than those used in this study. A recent study examined the influence of applying $25 \mathrm{ng} / \mathrm{ml}$ BDNF acutely or introducing it stepwise slowly to hippocampal slice cultures [53]. Total trkB levels were unaltered with both protocols, but acute application decreased surface trkB and triggered only a transient increase in trkB phosphorylation. Slow application did not decrease surface trkB levels and led to a maintained increase in phosphorylated BDNF. Although the collagen in which the ganglia are embedded has the indicated concentration of BDNF from the time of plating, whether peripheral neurons recovering from dissection respond similarly to hippocampal neurons that have been cultured for 2 weeks prior to BDNF treatment remains to be determined. High levels of BDNF may also disrupt motility-promoting interactions between the growth cone and other cells (including neurites) or the collagen I gel matrix [54]. In support of the latter possibility, there is clearly a change in morphology of the outgrowth that presumably reflects altered interactions between the growth cones and their surroundings: at E15 and E18, outgrowth promoted by intermediate concentrations of BDNF was segregated into discrete fascicles, whereas outgrowth in the presence of high concentrations of BDNF emanated from the ganglion in a more continuous, web-like pattern (fig. 1a, b). Compared to embryonic ganglia, P1-7 ganglia were less affected by high concentrations of BDNF (100-200 $\mathrm{ng} / \mathrm{ml})$ both in terms of the morphology and the length of outgrowth. Outgrowth at postnatal stages was also significantly longer than that observed for embryonic cultures. It will be important to determine whether embryonic and postnatal neurons differ in their levels of trkB, p75, or BDNF.

We used in vitro assays to demonstrate that BDNF is a chemoattractant for embryonic geniculate neurites. When ganglia were dissected at E15, BDNF-soaked beads promoted outgrowth that was nearly exclusively directed toward the bead. The bias was also evident if $25 \mathrm{ng} / \mathrm{ml}$ of BDNF was present in the bath, indicating that neurites can distinguish gradients over a wide range of concentrations despite a high background level of BDNF. BDNF continued to act as an attractant at E18, although the outgrowth bias ratio was less than at E15. At both E15 and E18, neurite outgrowth toward the BDNF bead was faster than growth away from the bead, even when the same amount or less BDNF was encountered. Despite this robust bias, the majority of neurites do not make sharp turns toward the bead. A recent analysis of neurite extension in the presence of gradients of NGF that differ in slope suggests that persistent turning toward a source of a chemotropic factor is primarily observed when the slope of the gradient is high (enabling growth cones to reliably distinguish concentrations on each side of the growth cone) [55]. Mortimer et al. [55] proposed an alternative mechanism, "growth rate modulation", to explain highly biased neurite outgrowth characterized by inconsistent turning responses distributed over gradients with low slopes. In this model, turning occurs randomly, but turns toward the source result in more rapid advance than turns away from the source. Our observations are consistent with this model. We also demonstrated that neurites do not grow beyond BDNF beads at these stages. These observations indicate that the tropic influence of BDNF dominates the trophic influence at initial targeting/target penetration stages. These results differ from those obtained in a study of the effects of NGF gradients on mouse trigeminal neurite outgrowth [49]. That study showed that trigeminal neurite outgrowth was biased toward NGF beads (at low doses) only at the equivalent of E15; no bias was observed at the equivalent of E18, just after target contact. This difference could be attributable to species or neuronal type, but it may also be related to different functions of these neurotrophins. NGF is present along the pathway explored by many trigeminal afferents and is critical for maintaining axon growth (trophism) [56], whereas BDNF is implicated as a target-derived attractant.

One cannot assume that in vitro results are relevant to the in vivo setting. All of our tropism data were gathered using collagen I gels and serum-containing medium, which is undoubtedly different from the in vivo setting. The responses of growth cones to attractants and repellents are influenced by other diffusible molecules and by the substratum [54,57], so this is not a trivial concern. It is equally unreasonable to dismiss in vitro studies as artifacts with no relevance to the in vivo phenomenon. As discussed next, our current results support a straightforward interpretation of the in vivo neurotrophin perturbation studies. Substantial parallels between in vivo and in vitro observations were also found in our previous studies of other diffusible cues [58-60]. Our in vitro findings combined with localization data would have predicted the results from in vivo studies.

The bias in outgrowth by BDNF gradients is highest just prior to the invasion of the target epithelium by taste afferents, and persists until shortly after target penetration. Combined with in vivo studies showing that geniculate axons stop extending prior to reaching gustatory papillae in BDNF-/- mice [12] and misexpression studies that show that geniculate axons invade tissues that over- 
express BDNF [4], our findings support a model in which BDNF directly attracts axons to pregustatory epithelium during the final stage of targeting. None of these observations excludes roles for other, yet to be identified, attractants during intralingual targeting. The existence of other targeting molecules is suggested by the finding that a subset of papillae is properly innervated in mice lacking epithelial BDNF [12]. However, improper targeting was also observed, so it is possible that proper 'targeting' in BDNF-/- mice was due primarily to selective stabilization of randomly targeting geniculate axons.

Two observations raise the possibility that BDNF could act as a stop signal during initial innervation, preventing the axons from continuing to grow once they penetrate the epithelium. E15 and E18 neurites that contacted beads appeared to stop advancing rather than encircling the bead or growing beyond it, and high concentrations $(200 \mathrm{ng} / \mathrm{ml})$ of BDNF reduced or eliminated geniculate neurite extension. It seems unlikely that such high concentrations would be encountered in vivo, but it is difficult to determine in vivo concentrations of secreted proteins. Neurotrophic factors may accumulate in the extracellular matrix or be held at high concentration on cell surfaces [25]. Inhibition of neurite growth was also reported for NGF using mouse trigeminal neurons [49].

At postnatal stages, gradients of BDNF do not significantly bias neurite outgrowth length, although it does bias the density of outgrowth. The greater density could result from more neurons extending neurites or the same number of neurons extending more neurites. Regardless, these results suggest that BDNF switches from acting as a chemoattractant to acting as a predominantly trophic factor. Neurotrophic factors promote regeneration following injury through adulthood [61], so understanding how the response to neurotrophic factors is altered during postnatal development may have therapeutic applications.

We have stressed the correspondence between our findings and observations of the innervation of the tongue, but we note that the geniculate ganglion contains taste neurons that innervate taste buds in the palate, as well as somatosensory neurons that innervate the skin of the outer ear $[62,63]$. Although the distribution of BDNF mRNA in palatal tissues has not been published, innervation of palatal taste buds in BDNF-/- animals is compromised similarly (albeit to a lesser extent) to innervation of lingual taste buds [12]. It is not known if the geniculate somatosensory neurons respond in the same way to $\mathrm{BDNF}$ as the taste neurons, or if they are more similar to trigeminal somatosensory neurons. It seems unlikely that these neurons are closely similar to trigeminal neurons because NGF and NT-3 do not support neurite extension from geniculate explants at targeting stages, but both of these neurotrophins support neurite extension from trigeminal neurons [59] and are present during and required for normal innervation $[6,9,10,47,64]$. It will be helpful to develop markers for these populations of geniculate neurons so that differences in the responses of their neurites can be studied in vitro.

In summary, our data support a role for BDNF in attracting taste axons into pre-gustatory epithelium during initial innervation. Our data do not support a guidance role for BDNF after birth, nor do they exclude such a role. It will be important to determine whether somatosensory afferents that terminate adjacent to taste buds are also attracted toward the epithelium by neurotrophic factors such as NT-3, which becomes localized in nongustatory lingual epithelium at the time that trigeminal afferents begin to invade. It will also be important to determine whether NT-4, which acts through the same receptors as $\mathrm{BDNF}$, is tropic for geniculate neurites during development. Although NT- 4 does not appear to be concentrated in taste axon targets [47] and innervation is normal for the surviving geniculate neurons in NT-4 knockout mice, overexpression of NT-4 in the lingual epithelium interferes with penetration by geniculate axons $[12,14]$.

\section{Acknowledgements}

The $2 \mathrm{H} 3$ antibody developed by J. Dodd and T.M. Jessell (Neuron 1:105) was obtained from the Developmental Studies Hybridoma Bank developed under the auspices of the NICHD and maintained by the University of Iowa. This work was supported by a research grant to M.W.R. from the NIDCD, 1R15DC009043-01.

References

1 Mbiene JP: Taste placodes are primary targets of geniculate but not trigeminal sensory axons in mouse developing tongue. J Neurocytol 2004;33:617-629.

-2 Mbiene JP, Mistretta CM: Initial innervation of embryonic rat tongue and developing taste papillae: nerves follow distinctive and spatially restricted pathways. Acta Anat (Basel) 1997;160:139-158.

- 3 Farbman AI, Mbiene JP: Early development and innervation of taste bud-bearing papillae on the rat tongue. J Comp Neurol 1991; 304:172-186.

4 Krimm RF: Factors that regulate embryonic gustatory development. BMC Neurosci 2007; 8(suppl 3):S4. 
5 Lopez GF, Krimm RF: Refinement of innervation accuracy following initial targeting of peripheral gustatory fibers. J Neurobiol 2006;66:1033-1043.

-6 Nosrat IV, Lindskog S, Seiger A, Nosrat CA: Lingual BDNF and NT-3 mRNA expression patterns and their relation to innervation in the human tongue: similarities and differences compared with rodents. J Comp Neurol 2000;417:133-152.

7 Nosrat CA, Ebendal T, Olson L: Differential expression of brain-derived neurotrophic factor and neurotrophin $3 \mathrm{mRNA}$ in lingual papillae and taste buds indicates roles in gustatory and somatosensory innervation. J Comp Neurol 1996;376:587-602.

$\checkmark 8$ Nosrat CA, Olson L: Brain-derived neurotrophic factor mRNA is expressed in the developing taste bud-bearing tongue papillae of rat. J Comp Neurol 1995;360:698-704.

$\checkmark 9$ Nosrat IV, Agerman K, Marinescu A, Ernfors P, Nosrat CA: Lingual deficits in neurotrophin double knockout mice. J Neurocytol 2004;33:607-615.

-10 Nosrat CA, Blomlof J, ElShamy WM, Ernfors $\mathrm{P}$, Olson L: Lingual deficits in BDNF and NT3 mutant mice leading to gustatory and somatosensory disturbances, respectively. Development 1997;124:1333-1342.

- 11 Zhang C, Brandemihl A, Lau D, Lawton A, Oakley B: BDNF is required for the normal development of taste neurons in vivo. Neuroreport 1997;8:1013-1017.

- 12 Ma L, Lopez GF, Krimm RF: Epithelialderived brain-derived neurotrophic factor is required for gustatory neuron targeting during a critical developmental period. J Neurosci 2009;29:3354-3364.

13 Ringstedt T, Ibanez CF, Nosrat CA: Role of brain-derived neurotrophic factor in target invasion in the gustatory system. J Neurosci 1999;19:3507-3518.

14 Lopez GF, Krimm RF: Epithelial overexpression of BDNF and NT4 produces distinct gustatory axon morphologies that disrupt initial targeting. Dev Biol 2006;292:457-468.

15 Krimm RF, Miller KK, Kitzman PH, Davis BM, Albers KM: Epithelial overexpression of BDNF or NT4 disrupts targeting of taste neurons that innervate the anterior tongue. Dev Biol 2001;232:508-521.

-16 Patel TD, Kramer I, Kucera J, Niederkofler V, Jessell TM, Arber S, Snider WD: Peripheral NT3 signaling is required for ETS protein expression and central patterning of proprioceptive sensory afferents. Neuron 2003;38: 403-416.

17 Markus A, Patel TD, Snider WD: Neurotrophic factors and axonal growth. Curr Opin Neurobiol 2002;12:523-531.

18 Genc B, Ozdinler PH, Mendoza AE, Erzurumlu RS: A chemoattractant role for NT-3 in proprioceptive axon guidance. PLoS Biol 2004;2:e403.
19 Ulupinar E, Jacquin MF, Erzurumlu RS: Differential effects of NGF and NT-3 on embryonic trigeminal axon growth patterns. J Comp Neurol 2000;425:202-218.

20 Tessarollo L, Coppola V, Fritzsch B: NT-3 replacement with brain-derived neurotrophic factor redirects vestibular nerve fibers to the cochlea. J Neurosci 2004;24:2575-2584.

21 Fritzsch B, Tessarollo L, Coppola E, Reichardt LF: Neurotrophins in the ear: their roles in sensory neuron survival and fiber guidance. Prog Brain Res 2004;146:265-278.

22 LeMaster AM, Krimm RF, Davis BM, Noe T, Forbes ME, Johnson JE, Albers KM: Overexpression of brain-derived neurotrophic factor enhances sensory innervation and selectively increases neuron number. J Neurosci 1999;19:5919-5931.

-23 Tucker KL, Meyer M, Barde YA: Neurotrophins are required for nerve growth during development. Nat Neurosci 2001;4:2937.

24 Ming G, Lohof AM, Zheng JQ: Acute morphogenic and chemotropic effects of neurotrophins on cultured embryonic Xenopus spinal neurons. J Neurosci 1997;17:78607871.

25 Mai J, Fok L, Gao H, Zhang X, Poo MM: Axon initiation and growth cone turning on bound protein gradients. J Neurosci 2009;29: 7450-7458.

26 Gehler S, Shaw AE, Sarmiere PD, Bamburg JR, Letourneau PC: Brain-derived neurotrophic factor regulation of retinal growth cone filopodial dynamics is mediated through actin depolymerizing factor/cofilin. J Neurosci 2004;24:10741-10749.

27 O'Connor R, Tessier-Lavigne M: Identification of maxillary factor, a maxillary processderived chemoattractant for developing trigeminal sensory axons. Neuron 1999;24: 165-178.

28 Eide FF, Vining ER, Eide BL, Zang K, Wang XY, Reichardt LF: Naturally occurring truncated trkB receptors have dominant inhibitory effects on brain-derived neurotrophic factor signaling. J Neurosci 1996;16:31233129.

29 Conover JC, Erickson JT, Katz DM, Bianchi LM, Poueymirou WT, McClain J, Pan L, Helgren M, Ip NY, Boland P, et al: Neuronal deficits, not involving motor neurons, in mice lacking BDNF and/or NT4. Nature 1995;375: 235-238.

30 Liu X, Ernfors P, Wu H, Jaenisch R: Sensory but not motor neuron deficits in mice lacking NT4 and BDNF. Nature 1995;375:238241.

31 Zhang X, Poo MM: Localized synaptic potentiation by BDNF requires local protein synthesis in the developing axon. Neuron 2002;36:675-688.

- 32 Botchkarev VA, Yaar M, Peters EM, Raychaudhuri SP, Botchkareva NV, Marconi A, Raychaudhuri SK, Paus R, Pincelli C: Neurotrophins in skin biology and pathology. J Invest Dermatol 2006;126:1719-1727.
33 de Carlos F, Cobo J, Germana G, Silos-Santiago I, Laura R, Haro JJ, Farinas I, Vega JA: Abnormal development of pacinian corpuscles in double trkB;trkC knockout mice. Neurosci Lett 2006;410:157-161.

34 Kirstein M, Farinas I: Sensing life: regulation of sensory neuron survival by neurotrophins. Cell Mol Life Sci 2002;59:1787-1802.

- 35 Tuttle R, O’Leary DD: Neurotrophins rapidly modulate growth cone response to the axon guidance molecule, collapsin-1. Mol Cell Neurosci 1998;11:1-8.

- 36 Ming G, Song H, Berninger B, Inagaki N, Tessier-Lavigne M, Poo M: Phospholipase Cgamma and phosphoinositide 3-kinase mediate cytoplasmic signaling in nerve growth cone guidance. Neuron 1999;23:139-148.

-37 Dontchev VD, Letourneau PC: Nerve growth factor and semaphorin $3 \mathrm{~A}$ signaling pathways interact in regulating sensory neuronal growth cone motility. J Neurosci 2002;22: 6659-6669.

38 Yee CL, Jones KR, Finger TE: Brain-derived neurotrophic factor is present in adult mouse taste cells with synapses. J Comp Neurol 2003;459:15-24.

39 Beidler LM, Smallman RL: Renewal of cells within taste buds. J Cell Biol 1965;27:263272.

40 Montavon P, Hellekant G, Farbman A: Immunohistochemical, electrophysiological, and electron microscopical study of rat fungiform taste buds after regeneration of chorda tympani through the non-gustatory lingual nerve. J Comp Neurol 1996;367:491502 .

41 Oakley B: Reformation of taste buds by crossed sensory nerves in the rat's tongue. Acta Physiol Scand 1970;79:88-94.

-42 Rochlin MW, Farbman AI: Trigeminal ganglion axons are repelled by their presumptive targets. J Neurosci 1998;18:6840-6852.

43 Slavkin H, Nuckolls G, Shum L: Craniofacial development and patterning. Methods Mol Biol 2000;136:45-54.

44 Mbiene JP, Farbman AI: Evidence for stimulus access to taste cells and nerves during development: an electron microscopic study. Microsc Res Tech 1993;26:94-105.

45 Lumsden AG, Davies AM: Chemotropic effect of specific target epithelium in the developing mammalian nervous system. Nature 1986;323:538-539.

-46 Lumsden AG, Davies AM: Earliest sensory nerve fibres are guided to peripheral targets by attractants other than nerve growth factor. Nature 1983;306:786-788.

-47 Nosrat CA: Neurotrophic factors in the tongue: expression patterns, biological activity, relation to innervation and studies of neurotrophin knockout mice. Ann N Y Acad Sci 1998;855:28-49.

48 Zou H, Ho C, Wong K, Tessier-Lavigne M: Axotomy-induced Smadl activation promotes axonal growth in adult sensory neurons. J Neurosci 2009;29:7116-7123. 
-49 Ozdinler PH, Ulupinar E, Erzurumlu RS: Dose and age-dependent axonal responses of embryonic trigeminal neurons to localized NGF via p75NTR receptor. J Neurobiol 2005; 62:189-206.

-50 Griffin CG, Letourneau PC: Rapid retraction of neurites by sensory neurons in response to increased concentrations of nerve growth factor. J Cell Biol 1980;86:156-161.

51 Conti AM, Fischer SJ, Windebank AJ: Inhibition of axonal growth from sensory neurons by excess nerve growth factor. Ann Neurol 1997;42:838-846.

- 52 Xu B, Michalski B, Racine RJ, Fahnestock M: The effects of brain-derived neurotrophic factor (BDNF) administration on kindling induction, Trk expression and seizure-related morphological changes. Neuroscience 2004;126:521-531.

- 53 Ji Y, Lu Y, Yang F, Shen W, Tang TT, Feng L, Duan S, Lu B: Acute and gradual increases in BDNF concentration elicit distinct signaling and functions in neurons. Nat Neurosci 2010;13:302-309.
54 Song HJ, Poo MM: Signal transduction underlying growth cone guidance by diffusible factors. Curr Opin Neurobiol 1999;9:355363.

55 Mortimer D, Pujic Z, Vaughan T, Thompson AW, Feldner J, Vetter I, Goodhill GJ: Axon guidance by growth-rate modulation. Proc Natl Acad Sci USA 1998;107:5202-5207.

-56 Patel TD, Jackman A, Rice FL, Kucera J, Snider WD: Development of sensory neurons in the absence of NGF/TrkA signaling in vivo. Neuron 2000;25:345-357.

-57 Hopker VH, Shewan D, Tessier-Lavigne M, Poo M, Holt C: Growth-cone attraction to netrin-1 is converted to repulsion by laminin-1. Nature 1999;401:69-73.

58 Vilbig R, Cosmano J, Giger R, Rochlin MW: Distinct roles for Sema3A, Sema3F, and an unidentified trophic factor in controlling the advance of geniculate axons to gustatory lingual epithelium. J Neurocytol 2004;33:591606.

59 Dillon TE, Saldanha J, Giger R, Verhaagen J, Rochlin MW: Sema3A regulates the timing of target contact by cranial sensory axons. J Comp Neurol 2004;470:13-24.
60 Rochlin MW, O’Connor R, Giger RJ, Verhaagen J, Farbman AI: Comparison of neurotrophin and repellent sensitivities of early embryonic geniculate and trigeminal axons. J Comp Neurol 2000;422:579-593.

61 Gordon T. The role of neurotrophic factors in nerve regeneration. Neurosurg Focus 2009;26:E3.

62 Miller IJ Jr, Gomez MM, Lubarsky EH. Distribution of the facial nerve to taste receptors in the rat Chem Senses Flavor 1978;3:397411.

63 Miller IJ Jr, Spangler KM. Taste bud distribution and innervation on the palate of the rat. Chem Senses 1982;7:99-108.

64 Nosrat CA, Olson L. Changes in neurotrophin-3 messenger RNA expression patterns in the prenatal rat tongue suggest guidance of developing somatosensory nerves to their final targets. Cell Tissue Res 1998;292:619623.

65 Streiner DL. Maintaining standards: differences between the standard deviation and standard error, and when to use each. Can J Psychiatry 1996;41:498-502. 